tising of the social conscience. We hope to see a continuation of these valuable essays in scientific synthesis, and we would take this opportunity of wishing the author success in his disinterested editorship of Scientia, which is an indubitable factor towards true pacifism.

\section{MATHEMATICAL BOOKS.}

(I) Theory of Maxima and Minona. By Prof. Harris Hancock. Pp. xiv + 193. (Boston (Mass.), London, etc. : Ginn and Co., rgr7.) Price Ios. $6 d$. net.

(2) Analytic Geometry and Calculus. By.Profs. F. S. Woods and F. H. Bailey. Pp. xi+5i6. (Boston (Mass.), London, etc. : Ginn and Co., I9r7.) Price ros. 6d. net.

(I) THE theory of maxima and minima contains pitfalls into which have fallen such well-known mathematicians as Lagrange, Bertrand, Serret, and Todhunter. A peculiar interest, therefore, is attached to the subject, and the reader will find Prof. Hancock's book well worth his study. Except that there is no reference to calculus of variations, the author has succeeded in covering the ground fairly thoroughly, and that without allowing the argument to be anywhere tedious. He gives many references, and a few quite interesting examples.

After a short investigation of maxima and minima of functions of a single variable, he gives in some detail the methods of Scheeffer and von Dantscher, which introduced rigour into the discussion of functions of two or three variables. The theory here is intimately connected with the theory of quadratic forms and singularities of higher plane curves. The author seems not to have read such books as Bromwich's "Quadratic Forms," Hilton's “Linear Substitutions," or Muth's "Elementartheilar," which would have enabled him in places to simplify his treatment of quadratic forms. In tracing a plane curve near a singularity, the author should have made use of Newton's diagram. He should also have avoided such a phrase as "cusps of the first and second kind," which implies that the cusps in question are comparable, whereas the latter is a singularity of much higher complexity than the former.

The chapter on relative maxima and minima is especially interesting. The discussion usually given in the text-books is very scanty, and the fuller treatment here given is very welcome. A valuable point is made in $\$ \$ 98$-ro7. The usual proof that the maximum triangle inscribed in a given circle is equilateral runs as follows: "If not, suppose $\mathrm{ABC}$ to be the greatest triangle. If $\mathrm{AB} \neq \mathrm{AC}$, let $\mathrm{D}$ bisect the arc $\mathrm{BAC}$. Then the triangle $\mathrm{BDC}>\mathrm{BAC}$, etc." Is this argument admissible? The reader may compare the following reasoning, due to an Italian author: "Unity is the greatest integer. For, if not, suppose $n(\neq \mathrm{I})$ the greatest. Then $n^{2}>n$, etc." The proofs run parallel, but the tacit assumption (a greatest triangle or integer exists) is lawful in one case and not in the other.

$$
\text { NO. } 255 \mathrm{I} \text {, VOL. IO2] }
$$

(2) This work is a revision and abridgment of the authors' two-volume "Course in Mathematics. for Students of Engineering and Applied Science,'” and is intended to occupy a two years' course for an average college class. The book does not give the impression of being especially suited to the needs of students of applied science, except for the fact that examples are included on finding centre of gravity, centre of pressure, and so on. In the main the book is apparently simply a course on pure mathematics designed for the American undergraduate. As such it may be commended as quite clear and readable, and it is furnished with some 2000 well-chosen examples. Naturally it is possible to criticise certain portions on the ground of absence of rigidity. But probably the authors have hit the happy mean between a slovenliness which demoralises the beginner and a precision which terrifies him.

It is interesting to contrast the American and English ideas of a suitable syllabus for the first two years of a "pass " mathematical course. The Americans include the co-ordinate geometry of straight line and plane; but the rest of the syllabus consists almost entirely of the calculus and elementary differential equations. Even the circle and conic receive no more than a passing mention; and very little algebra is inserted, such subjects as determinants and the theory of equations beingdeferred for subsequent study. Contrast this with a certain English B.A. course, which demands no calculus whatever, but requires the "simple properties of conic sections, including a discussion of the general equation of the second degree and the methods of projection "' The book under review may give the student a somewhat false idea of the importance of the conic (it is mentioned casually along with the witch, the cissoid, and the strophoid), and he may find partial differentiation studied by means of three-dimensional coordinate geometry a little too hard for him. But, nevertheless, English teachers have very much to learn from their allies.

H. H.

\section{OUR BOOKSHELF.}

The Botany of Iceland. Edited by Dr. L. Kolderup Rosenvinge and Dr. Eug. Warming. Part ii. 3. Ernst $\varnothing$ strup : "Marine Diatoms from the Coasts of Iceland.", 4. Aug. Hesselbo: "The Bryophyta of Iceland." Pp. 348-675. (Copenhagen : J. Frimodt; London: J. Wheldon and Co., I9i8.) Price iss. net.

Thus part completes vol. i. of "The Botany of Iceland," the first part of which was issued in two sections, one on "The Marine Algal Vegetation," by $H$. Jónsson, in Igr2, and a second on "The Physical Geography of the Island," in Igr4.

The list of marine diatoms from the coasts of Iceland comprises 209 species and varieties; seven species and a number of varieties are here described as new. Mr. Østrup gives a tabular list showing the universal distribution of the forms, as well as their distribution on the different parts of the coasts of Iceland from which it 